\title{
Por que tecelões e metalúrgicos vão aos tribunais? - posição da indústria e reclamações ao judiciário trabalhista entre as décadas de 1940 e 1960
}

\section{Valeria Marques Lobo*}

Resumo: O artigo analisa o uso da Justiça do Trabalho por têxteis e metalúrgicos, entre os anos de 1940 e 1960, a partir dos processos impetrados por trabalhadores das duas categorias à Junta de Conciliação e Julgamento (Vara do Trabalho) de Juiz de Fora. Nesse período, a transição para a indústria pesada teve impacto sobre a configuração da estrutura ocupacional da sociedade brasileira e sobre o mercado de trabalho desse município, bem como sobre a composição das categorias profissionais analisadas, o que tende, supostamente, a afetar o comportamento dos atores, repercutindo na formulação de demandas e, por conseguinte, na relação que eles estabelecem com o Judiciário trabalhista.

Palavras-chave: Mercado de Trabalho - Têxteis - Metalúrgicos - Justiça do Trabalho

Abstract: The article analyzes the use of the Labour Court for textile workers and factory workers, between 1940 and 1960, based on lawsuits filed by workers of the two categories to the Board of Conciliation and Judgement (Labour Court) of Juiz de Fora. During this period, the transition to heavy industry has an impact on the configuration of the occupational structure of Brazilian society, on the labour market of Juiz de Fora, as well as on the composition of occupational categories analyzed, which presumably affected the actors' behavior, resulting in the formulation of demands, therefore how the workers stablish their relationship with the labour court.

Keywords: Labour market - Textile workers - Factory workers - Labour Court

\section{Introdução}

A Justiça do Trabalho, no Brasil, foi instituída por meio da legislação trabaIhista fixada no país durante o Primeiro Governo Vargas. O objetivo desse primeiro

* Professora do Programa de Pós-graduação em História, da Universidade Federal de Juiz de Fora (MG). A pesquisa que resultou neste artigo contou com financiamento do CNPq e foi, em parte, realizada no âmbito do estágio pós-doutoral pelo Departamento de Economia do CEDEPLAR, sob a supervisão do Prof. Dr. Marcelo Magalhães Godoy. 
mandato, ao regulamentar o direito do trabalho e estabelecer uma instituição destinada a intermediar as relações de trabalho, era promover colaboração de classes e, por conseguinte, a paz social considerada necessária ao desenvolvimento urbano e industrial do país. Essa intenção é nítida em diversos pronunciamentos de Vargas, a exemplo do que se segue:

o melhor meio de garanti-lo [o capital] está, justamente, em transformar o proletariado numa força orgânica de cooperação com o Estado, e não o deixar, pelo abandono da lei, entregue à ação dissolvente de elementos perturbadores. ${ }^{1}$

Tal objetivo, ilustrado pelo discurso acima, é reconhecido pela quase totalidade da literatura referente ao tema. Contudo, se há convergência entre as abordagens referentes ao período quanto às razões que motivaram o governo Vargas a criar um ministério do trabalho, uma legislação trabalhista extremamente detaIhada e uma instituição destinada a mediar as relações de trabalho, transferindo o conflito de classes da esfera do mercado para o âmbito do estado, o mesmo não se pode afirmar em relação aos efeitos efetivos dessas medidas sobre os trabalhadores e sobre as relações de trabalho.

Embora muitos estudiosos venham se debruçando sobre vastos volumes documentais, a fim de descortinar o mundo do trabalho desde os anos de $1930-\mathrm{e}$ muito se tenha avançado na compreensão acerca da capacidade de associação e de mobilização dos trabalhadores para a ação coletiva, suas principais demandas, sua experiência cotidiana nas ruas, nos sindicatos e nos locais de trabalho, suas culturas políticas - , há ainda vários aspectos a serem elucidados.

Uma dessas lacunas refere-se à participação dos trabalhadores na burocracia estatal ou nas instituições que oferecem suporte ao modelo de intermediação de interesses brasileiros. A Justiça do Trabalho é, provavelmente, a instituição mais importante desse modelo. No entanto, pouco se sabe acerca do papel desempenhado ao longo de sua trajetória por essa que é uma das mais longevas e sólidas instituições do país, em que pesem os esforços nessa direção, boa parte dos quais produziu resultados que serão mencionados ao longo do presente artigo.

Visando contribuir para a compreensão acerca das relações de trabalho no Brasil, das relações que os trabalhadores estabelecem com o estado e da própria história do Judiciário trabalhista no Brasil, este artigo analisa o comportamento, na Justiça do Trabalho, de trabalhadores têxteis e metalúrgicos do município de Juiz de Fora, entre as décadas de 1940 e 1960. O objetivo é relacionar as diferenças que se observam entre as ações dessas categorias para com a Justiça do Trabalho e a situação da indústria têxtil e metalúrgica no município durante o período indicado.

O corpo do texto divide-se em duas partes. Inicialmente, analisa-se a história da Justiça do Trabalho no país, no intuito de compreender certas peculiaridades da instituição. As fontes que subsidiaram tal abordagem são, sobretudo, bibliográficas. Em seguida, procede-se a uma análise quantitativa do uso da Justiça do Trabalho pelas categorias mencionadas, na tentativa de compreender se e em que medida as especificidades de cada ramo se refletem no uso que os trabalhadores das distintas categorias fazem do judiciário trabalhista. A pesquisa que deu origem a esta análise apoiou-se em um grande volume de processos trabalhistas, que comportam ações impetradas à Junta de Conciliação e Julgamento de Juiz de

1 Apud LOWY, M. Do Movimento Operário Independente ao Sindicalismo de Estado. In: LOWY, M. (et al.) Introdução a uma História do Movimento Operário Brasileiro no Século XX. Belo Horizonte: Vega, 1980, p. 30. 
Fora, posteriormente Vara do Trabalho, no período compreendido entre a instalação da Junta no município, em 1944, e o Golpe de 1964.

A escolha do período compreendido entre as décadas de 1940 e 1960 como foco da análise e das categorias têxtil e metalúrgica como objeto de estudo deve-se, sobretudo, ao fato de tratar-se de um contexto de transição da industrialização brasileira, marcado pela passagem da industrialização restringida para a industrialização pesada, processo que se reflete em Juiz de Fora, a despeito das peculiaridades da evolução da economia local. Tal processo produz impacto sobre a configuração da estrutura ocupacional da sociedade brasileira e sobre o mercado de trabalho de Juiz de Fora, bem como sobre a composição das categorias profissionais analisadas ${ }^{2}$, com efeitos sobre o comportamento de empresários e trabalhadores.

\section{Justiça do Trabalho: História e particularidades}

A implantação da Justiça do Trabalho no Brasil ocorre em meio ao processo de fixação da legislação sindical e trabalhista, durante o primeiro governo Vargas. ${ }^{3}$ Não obstante ter sido efetivamente instalada apenas em 1941, a criação de um organismo dessa natureza já constava na pauta e nos debates constituintes de 1934, dois anos após a implantação das Comissões Mistas de Conciliação e Julgamento ${ }^{4}$, e figurava na Carta de 1937, quando foram introduzidos "mecanismos de enrijecimento da estrutura sindical e de seu controle, como a unicidade, o imposto compulsório, o enquadramento sindical"' '. A regulamentação da Justiça do Trabalho, por sua vez, seria objeto do decreto-lei n. ${ }^{\circ} 1.237$, fixado em primeiro de maio de 1939.

Nos primeiros anos, a instituição esteve vinculada ao Poder Executivo, via Ministério do Trabalho. Elina Pessanha e Regina Morel destacam que, nesse período, sua estrutura era composta pelas Juntas de Conciliação e Julgamento (posteriormente Varas do Trabalho), na base; pelos Conselhos Regionais do Trabalho (atuais Tribunais Regionais do Trabalho), no nível intermediário; e pelo Conselho Nacional do Trabalho (atual Tribunal Superior do Trabalho), no topo. As instâncias tinham composição tripartite, contando, além dos profissionais com formação em Direito, com representações patronais e dos empregados. Em 1946, a Justiça do Trabalho passou à órbita do Judiciário, adquirindo autonomia em relação ao Executivo, "competência específica, poder normativo e Ministério Público correspondente junto ao Ministério Público da União”6. Em 1999, a representação classista foi extinta, por meio da Emenda Constitucional n. ${ }^{\circ} 24$.

Desde os anos de 1940, ainda de acordo com Pessanha e Morel, a carreira de juiz do trabalho obedece ao modelo geral de carreira da magistratura, embora a

2 Sobre a industrialização em Juiz de Fora no período, cf.: SOUZA PAULA, M. C. As Vicissitudes da Industrialização Periférica: o caso de Juiz de Fora (1930-1970). Dissertação (Mestrado em Ciência Política), UFMG, Belo Horizonte, 1976; PAULA, R. Z. A. História de Juiz de Fora: da Vanguarda de Minas à industrialização periférica. Tese (Doutorado em Economia), Campinas, UNICAMP, 2006.

3 Sobre o processo e o contexto de implementação da legislação trabalhista, cf.: SOUZA, S. F. Coagidos ou Subornados: trabalhadores, sindicatos, Estado e as leis do trabalho nos anos 1930. Tese (Doutorado em História), Campinas, UNICAMP, 2007. Cf., ainda, HALL, M. "Labor and the Law in Brazil”. In: LINDEN, M. V. e PRICE, R (Orgs.). The Rise and Development of Collective Labour Law. Bern/New York: Peter Lang, 2000.

4 Decreto n. 21.396, de 25/11/1932. Cf.: DELGADO, M. G. Curso de Direito do Trabalho. São Paulo: LTr, 2004, p. 111.

5 MOREL, R.; PESSANHA, E. A Justiça do Trabalho. Tempo Social. São Paulo, v. 19, n. 2, p. 87-109, 2007, p. 90.

6 Ibidem. 
Justiça do Trabalho tenha sido por muito tempo encarada como uma instância menor no âmbito do Poder Judiciário, e seus magistrados tiveram que esperar ainda algumas décadas para obter isonomia de salários e direitos em relação aos demais magistrados.7 Conforme Angela de Castro Gomes, essa "tradição de desprestígio" parte dos próprios magistrados e é atribuída às características intrínsecas ao Judiciário trabalhista ${ }^{8}$, muitas das quais preservadas até a atualidade, tais como a gratuidade, "a dispensa de advogados, a oralidade e a maior informalidade" dos atos processuais. ${ }^{9}$ Fernando Teixeira da Silva observa, por exemplo, que "o mobiliário e o arranjo espacial das salas de audiência compõem um quadro em tudo diferente da justiça comum" ${ }^{10}$, muito mais simples que os demais tribunais. Segundo Gomes, a cultura de desprestígio teria subsistido até pelo menos a Constituição de 1988 , quando a valorização dos direitos sociais e do trabalho marcam a reversão desta tradição. ${ }^{11}$

Em contrapartida ao desprestígio com que foi encarada pelos magistrados, a Justiça do Trabalho parece ter sido instituição extremamente valorizada pelos trabalhadores, os quais, desde a instalação das Juntas de Conciliação e Julgamento, recorriam com frequência cada vez maior aos tribunais trabalhistas para fazer valer seus direitos. Nesse ponto, é importante salientar que a Justiça do Trabalho não constituía um campo magnético que, ao mesmo tempo em que atraía os trabaIhadores, os afastava de outras arenas. Com efeito, particularmente em sistemas políticos abertos, a instituição parece ter representado apenas uma das frentes nas quais se travava a batalha entre Capital e Trabalho, mais do que uma alternativa à luta direta, distanciando-se das expectativas que informaram o projeto que engendrou a Justiça do Trabalho. ${ }^{12}$ Inspirado pelos princípios do corporativismo estatal, tal projeto visava conduzir para a esfera da burocracia de estado o conflito de classes, transformando os organismos de intermediação de interesses em entidades oficiais. De sua parte, a Justiça do Trabalho seria a instância destinada a dirimir os conflitos, sempre que ocorressem litígios, individuais ou coletivos, no mundo do trabalho. Buscava, com isso, mitigar a manifestação extrainstitucional da luta de classes, favorecendo, assim, o controle do estado sobre os trabalhadores, suas lideranças e sindicatos.

A fixação da Justiça do Trabalho enquadra-se no projeto de formação de um modelo de relações de trabalho que tem sido denominado pela literatura pertinente de legislado, em contraposição aos modelos negociados

7 PESSANHA, E. G. F.; MOREL, R. L. M. Magistrados do Trabalho no Brasil: entre a tradição e a mudança. Estudos Históricos. Rio de Janeiro, v. 37, 2006, p. 29-53. GOMES, Angela de Castro. Retrato Falado: a Justiça do Trabalho na visão de seus magistrados. Estudos Históricos. Rio de Janeiro, n. 37, 2006, p. 55-80.

8 GOMES, op. cit., p. 60.

9 PESSANHA; MOREL, 2006, p. 91.

10 SILVA, F. T. Nem crematório de fontes nem museu de curiosidades: por que preservar os documentos da Justiça do Trabalho. In: BIAVASCHI, M.; LUBBE, A.; MIRANDA, M. G. (Org.) Memória e Preservação de Documentos: direito do cidadão. São Paulo: LTr, 2007, p. 3.

11 GOMES, op. cit.

12 Entre os estudos que apontam indícios de que a presença da Justiça do Trabalho não inibia a luta por direitos em outras esferas, cf.: LOPES, J.S.L. A Tecelagem dos Conflitos na Cidade das Chaminés. São Paulo: Marco Zero, 1988; VARUSSA, J. R. Trabalho e Legislação: experiências e trabalhadores na Justiça do Trabalho (Jundiaí, décadas de 40 a 60). Tese (Doutorado em História). São Paulo: PUC (2002); CORRÊA, L. R. Trabalhadores Têxteis e Metalúrgicos a Caminho da Justiça do Trabalho: leis e direitos na cidade de São Paulo, 1953-1964. Dissertação (Mestrado em História), Campinas: UNICAMP, 2007; CORRÊA, L. R. A tessitura dos Direitos: patrões e empregados na Justiça do Trabalho. 1. ed. São Paulo: LTr, 2011. v. 1. 231p . PEREIRA NETO, M. L. A reinvenção do trabalhismo no vulcão do inferno. Um estudo sobre metalúrgicos e têxteis de São Paulo. Tese (Doutorado em História), USP, 2006. 
ou contratualistas. ${ }^{13}$ Segundo Adalberto Cardoso, no modelo legislado de relações de trabalho, o Direito do Trabalho regula tanto as relações individuais entre o empregador e cada um de seus empregados como as relações de direito coletivo, que regulam a organização sindical, a ação coletiva, a negociação coletiva etc. ${ }^{14}$ Sendo assim, tornava-se imperativo desenvolver uma legislação minuciosa, capaz de dar conta de situações diversas, descartando-se, por conseguinte, a necessidade da ação sindical. Nesse quadro, os agentes ficariam condicionados a buscar no estado a solução dos conflitos. Com efeito, o processo de regulamentação das relações de trabalho, durante os anos de 1930 e início da década de 1940, imprimiu no sistema brasileiro de relações de trabalho um tipo de relação entre Capital e Trabalho informado por uma legislação que, desde o início, é marcada por um caráter extremamente detalhado.

Tendo em vista seu papel de dirimir os conflitos decorrentes das relações entre empregadores e empregados, que estes possuem motivações variadas e que a legislação destinada a regular as relações de trabalho é vasta e minuciosa, a Justiça do Trabalho funcionaria como um catalisador, atraindo celeremente o conflito para o seu interior. Tal função foi desempenhada com propriedade pelo Judiciário trabalhista, o que pode ser atestado pelo crescimento exponencial de demandas encaminhadas à Justiça do Trabalho desde a sua fixação, ainda que, cumpre reiterar, sua presença não tenha inibido a manifestação do conflito em outras searas. ${ }^{15}$

A despeito de sua efetividade, a Justiça do Trabalho foi por diversas vezes objeto de controvérsias, tanto no âmbito do poder público como nos meios sindicais e empresariais. Quer por ter sido vista como uma instituição "a serviço da burguesia industrial, afundada em procedimentos burocráticos e manipulada pelo Estado", como destaca Larissa Corrêa ${ }^{16}$, quer por dispor de poder normativo, representação classista, ou ainda por seu caráter conciliatório, a instituição recebeu críticas de variados atores. Nos anos de 1990, o Judiciário trabalhista tornou-se alvo de severos ataques por parte do governo federal e de representantes do empresariado. Nesse período, como parte do discurso desregulamentador das relações de trabalho, que propunha a redução da interferência do estado nas relações entre Capital e Trabalho, e a subsequente transferência do conflito entre esses dois agentes para a esfera do mercado, chegou-se a postular a extinção da Justiça do Trabalho. ${ }^{17}$ Tal proposição encontrou resistência não apenas entre os magistrados da área, mas também no interior do Congresso Nacional, da Ordem dos Advogados do Brasil, bem como uma forte reação entre os trabalhadores.

13 Eduardo Noronha propõe uma tipologia das relações de trabalho polarizada entre os modelos legislados e os contratualistas e indica que o sistema brasileiro de relações de trabalho encaixa-se no modelo legislado, no qual observa-se uma "forte presença da lei na estruturação do mercado de trabalho", isto é, "dentre os três espaços normativos do mercado e das relações de trabalho, a lei predomina sobre os contratos coletivos e sobre as normas definidas unilateralmente pelas empresas". Cf.: NORONHA, E. G. O modelo legislado de relações de trabalho no Brasil. Dados. Rio de Janeiro, v. 43, n. 2, 2000, p. 241-290.

14 Para uma análise mais ampla acerca da relação entre a presença de tal modelo e a forte judicialização das relações de trabalho no Brasil, cf.: CARDOSO, A. M. A Década Neoliberal e a Crise dos Sindicatos no Brasil. São Paulo: Boitempo, 2003.

15 Entre 1944 e 1964, o número de processos acolhidos pela JCJ-JF aumentou continuamente, a cada ano. Entre 1964 e 1970, verifica-se um aumento anual ainda mais significativo. O acervo da Justiça do Trabalho em Juiz de Fora encontra-se no Arquivo Histórico do município.

16 Corrêa, op. cit., p. 14. Cf., ainda, FRENCH John. Afogados em Leis. São Paulo: Editora Fundação Perseu Abramo, 2001.

17 LOBO, V. M. Fronteiras da Cidadania: sindicatos e (des)mercantilização do trabalho no Brasil. Belo Horizonte: Argvmentvm, 2010. 
De todo modo, em que pese sua criação estar informada pelo objetivo de estabelecer um maior controle do estado sobre a ação dos trabalhadores e arrefecer o conflito entre Capital e Trabalho, a Justiça do Trabalho parece ter se transformado, no decorrer de sua evolução - e sobretudo em conjunturas autoritárias ou em momentos de crise do trabalho - , num instrumento caro aos trabalhadores. ${ }^{18}$ Ainda que por diversas vezes as sentenças sejam favoráveis ao empregador, que a presença de tal instância não seja suficiente para obrigar o empresário ao cumprimento da legislação durante a vigência do contrato de trabalho, e em que pese o fato de acordos posteriores ao seu término raramente assegurarem ao trabalhador os benefícios correspondentes ao previsto em lei, os trabalhadores brasileiros estão longe de admitir sua extinção. Em face disso, cumpre indagar acerca do peso dos aspectos simbólicos e materiais subjacentes à defesa da JT pelos trabaIhadores. No entanto, a despeito do interesse crescente despertado pelo objeto, o tema ainda é rarefeito nos meios acadêmicos brasileiros, sobretudo se contrastado a outros assuntos, e os poucos estudos pertinentes ainda não esgotaram essas questões. Embora ofereçam importantes pistas para a compreensão acerca do papel desempenhado pela JT, permanecem inúmeras lacunas, o que, inclusive, tem sido frequentemente reconhecido pelos próprios autores desses trabalhos.

Fato é que, embora a Justiça do Trabalho venha produzindo, no decorrer de seus setenta anos de existência, um volume imensurável de fontes documentais, durante muito tempo essa documentação foi praticamente ignorada por historiadores e sociólogos. Mesmo que nos últimos anos venha aumentando o interesse pelo tema nos meios acadêmicos, ainda há um longo caminho a percorrer, sobretudo se considerarmos a amplitude de possibilidades oferecidas pelos acervos do Judiciário trabalhista.

Além de permitir aos pesquisadores descortinar a história das relações de trabalho por meio da mediação jurídica e institucional do Judiciário trabalhista; o pensamento e os procedimentos dos magistrados; as diferentes interpretações da lei e dos direitos, segundo a visão dos trabalhadores e empresários, esses documentos elucidam aspectos importantes do processo de industrialização. Com efeito, algumas reclamações levam o juiz a designar peritos, a fim de analisar as mudanças no ambiente de trabalho decorrentes, por exemplo, da renovação do maquinário. Alguns relatórios de perícia atestam a realização de grandes reestruturações, produzindo impacto sobre o trabalhador, com a intensificação do trabalho, e gerando reclamações judiciais. Tendo em vista que nem sempre os documentos produzidos pelas fábricas foram preservados, os processos trabalhistas aparecem como uma das poucas alternativas para informar acerca daquelas mudanças.

Os processos trabalhistas permitem-nos, ainda, indagar acerca das relações que se estabelecem entre os trabalhadores, oferecendo, nesse caso, fortes indícios da existência de identidades operárias horizontais. ${ }^{19}$ Ao cabo, esses documentos fornecem pistas que permitem formular a hipótese de que as articulações entre os trabalhadores fugiam ao roteiro que engendrou todo o aparato sindical

18 Neste ponto, cumpre ressaltar que mesmo os trabalhadores rurais, no período em que permaneciam excluídos da legislação protetiva, viam na Justiça do Trabalho um instrumento importante para reduzir os prejuízos decorrentes dos desmandos dos proprietários, recorrendo com relativa frequência ao judiciário, inclusive o trabalhista. Sobre isso, ver referência à pesquisa de Clifford Welch em DEZEMONE, M. Do Cativeiro à Reforma Agrária: colonato, direitos e conflitos (1872-1987). Tese (Doutorado em História), Niterói: Universidade Federal Fluminense, 2008, p. 170.

19 NEGRO, A. L. "O que a Justiça do Trabalho não queimou: novas fontes para o estudo do trabalho no século XX”. Politeia: História e Sociologia. Vitória da Conquista. v. 6, n. 1, 2006, p. 193-209. 
e trabalhista do qual a Justiça do Trabalho é apenas uma parte e que tinha por objetivo engendrar entre os trabalhadores uma relação prioritária com o estado, em detrimento de relações horizontais que pudessem desencadear conflitos trabalhistas diretos.

Por outro lado, a análise dos processos trabalhistas permite-nos afirmar que, assim como são distintas as relações de trabalho que se processam no interior do espaço fabril e a luta por direitos em diferentes esferas, o comportamento dos agentes também varia no âmbito da Justiça do Trabalho. A diferença que se observa no comportamento dos atores pode ser atribuída, entre outros fatores, ao ramo de produção a que pertencem os contendores. Com o objetivo de contribuir para a identificação de tais diferenças, a seção seguinte apresenta uma análise quantitativa do uso da Justiça do Trabalho por têxteis e metalúrgicos. ${ }^{20}$

\section{Tecelões e metalúrgicos nos tribunais}

Antes de passar à análise, cumpre reiterar que a escolha do período compreendido entre as décadas de 1940 e 1960 como foco da análise e das categorias têxtil e metalúrgica como objeto de estudo justifica-se em face dos seguintes fatores: 1) esse é um contexto em que o movimento sindical encontra-se em grande atividade e no qual, dada a presença de um sistema político aberto, sobretudo a partir de 1945, a ação sindical ganha visibilidade; 2) por outro lado, esse é um momento de transição da industrialização brasileira, marcado pela passagem da industrialização restringida para a industrialização pesada, processo que se reflete em Juiz de Fora, não obstante as peculiaridades da evolução da economia local. De todo modo, essa transição tem impacto sobre a configuração da estrutura ocupacional da sociedade brasileira e sobre o mercado de trabalho de Juiz de Fora, bem como sobre a composição das categorias profissionais analisadas. ${ }^{21}$

No cenário econômico de Juiz de Fora, esse período coincide com a diversificação da estrutura industrial. Embora ainda predominem os ramos de produção têxtil e de alimentos, setores ligados à metalurgia, química e mecânica ganham importância. Do ponto de vista do mercado de trabalho, o período é marcado por elevada rotatividade da mão de obra na indústria têxtil ${ }^{22}$, o que pode ser atribuído, entre outros fatores, à reestruturação produtiva que se verifica no setor, com a introdução, em alguns casos, de tecnologia poupadora de mão de obra. ${ }^{23}$ Somado

20 Para se obter uma compreensão plena acerca das razões que levam indivíduos a recorrer ao judiciário contra seus patrões ou ex-patrões, deve-se considerar, conforme destaca Lygia Sigaud, "o quadro mais amplo das condutas dos indivíduos e das relações sociais nas quais estão inseridos". SIGAUD, L. M. Direito e Coerção Moral no Mundo dos Engenhos. Revista Estudos Históricos. Rio de Janeiro: FGV, v. 9, n. 18, p. 361-388, 1996, p. 362. Nesse sentido, reiteramos que o presente artigo dispõe de objetivos limitados, restringindo-se à análise quantitativa de questões relacionadas apenas às relações que se estabelecem no âmbito do processo produtivo e seus reflexos nas demandas ao judiciário.

21 Sobre a industrialização em Juiz de Fora no período, cf.: SOUZA PAULA, op. cit; PAULA, R. Z. A. op. cit.

22 PAULA, R. Z. A. op. cit., especialmente p. 350 e SS.

23 O processo de "reestruturação produtiva" da indústria têxtil na década de 1950 foi identificado, entre outros, por POCHMANN, M. Desempregados do Brasil. In: ANTUNES, R. (Org.). Riqueza e Miséria do Trabalho no Brasil. São Paulo: Boitempo, 2006, p. 59-73. Para o caso de Juiz de Fora, cf.: LOYOLA, M. A. Racionalizacao do Trabalho e Atitudes Operárias. Revista de Administração de Empresas, Rio de janeiro: FGV, v. 15, n. 6, 1975, p. 71-92; LOYOLA, M. A. Trabalho e Modernização na Indústria Têxtil. Revista de Administração de Empresas, Rio de janeiro: FGV, v. 14, n. 5, 1974, p. 19-31. O impacto disso sobre as formulações do movimento sindical foi analisado em LOBO, op. cit. Os processos trabalhistas atestam a existência do que estamos chamando de "reestruturação" em indústrias têxteis instaladas em Juiz de Fora, sobretudo aqueles que contêm anexados relatórios de peritos do trabalho, anteriormente mencionados. 
à baixa qualificação exigida do trabalhador da indústria têxtil, tal fenômeno gera insegurança no emprego, o que pode inibir o empregado a acionar a Justiça contra o empregador. Ao passo que a indústria metalúrgica, que adquire crescente importância no cenário econômico do período, baseia-se desde cedo no uso do capital intensivo e numa força de trabalho mais especializada e, portanto, mais escassa, de mais difícil substituição. ${ }^{24}$ Tais fatores, se não chegam a reduzir o desequilíbrio na correlação de forças entre Capital e Trabalho nessa categoria, em contraste com a categoria têxtil — contribuindo, hipoteticamente, para o aumento do poder sindical e para a redução da tendência patronal a evadir-se da norma -, no mínimo afeta o comportamento dos atores e condiciona o empregador do ramo metalúrgico a adotar uma postura particular diante da legislação, repercutindo, assim, no uso que o trabalhador faz da Justiça do Trabalho.

Por outras palavras, a constatação de que as relações de trabalho são distintas conforme o setor de produção, e que essas diferenças são caudatárias da própria posição que os trabalhadores de cada categoria profissional ocupam na estrutura produtiva do país, nos permite formular a hipótese de que têxteis e metalúrgicos fazem uso distinto do Judiciário trabalhista. Em boa medida, isso decorre da própria posição que os empregadores assumem diante da legislação trabalhista. Isto é, a análise dos processos sugere que os empresários do ramo têxtil tendem a burlar com mais regularidade as leis estritamente relacionadas à remuneração do trabalho, ao passo que os empresários da indústria metalúrgica parecem evadir-se com mais frequência das normas referentes ao tempo de trabaIho, ainda que por vezes elas possam estar também relacionadas à questão mais geral da remuneração.

A fim de testar a hipótese e identificar as diferenças entre as duas categorias, nos parágrafos seguintes, busca-se responder a indagações tais como as que se seguem: Qual é o tipo de reclamação mais frequente? E a mais recorrente segundo a categoria do reclamante? Qual é a situação mais frequente do reclamante (ativo ou demitido)? E a situação mais habitual do reclamante segundo a categoria? Qual é o tipo de reclamação mais frequente segundo a situação do reclamante? E o resultado mais costumeiro? Qual é o resultado mais frequente segundo a categoria do reclamante? E o tipo de ação mais frequente (coletiva ou individual) ${ }^{25}$ ? Qual é o tipo de ação mais recorrente segundo a categoria? E a reclamação mais comum segundo o tipo de ação? Qual é o resultado mais frequente segundo o tipo de ação?

Conforme indicamos, a estrutura ocupacional se reflete no comportamento de empresários e empregados em cada ramo industrial e isso tende a repercutir no conteúdo das demandas encaminhadas à Justiça do Trabalho. Reiteramos, contudo, que as análises processadas nesta seção baseiam-se em pesquisa quantitativa, a qual, embora não encerre todas as questões levantadas anteriormente, constitui um passo importante para que, sobretudo quando somada a pesquisas qualitativas futuras, se obtenha uma compreensão mais ampla acerca das razões que induzem os trabalhadores de diferentes categorias profissionais a acionarem a Justiça contra seus patrões.

24 SOUZA PAULA, op. cit; PAULA, op. cit.

25 A expressão "ação coletiva" é utilizada aqui para designar um conjunto de ações individuais idênticas ou os dissídios individuais plúrimos, que contemplam interesses individuais e concretos. Não se confunde, pois, com "dissídio coletivo", que contempla interesses abstratos e coletivos. No entanto, assim como nos dissídios coletivos, os conflitos individuais plúrimos também resultam de iniciativa sindical, ainda que o resultado diga respeito a cada reclamante individualmente e não ao conjunto da categoria. Cf.: DELGADO, op. cit., p. 1291 e ss. 
Considerando a totalidade dos registros, em torno de nove $\mathrm{mil}^{26}$, as questões relacionadas à remuneração do trabalho são mais frequentes para o conjunto dos trabalhadores, independente da categoria em que estão inseridos. Se agrupadas, observa-se que $47 \%$ das reclamações enquadram-se nestes tipos de ação: exigência de pagamento de abono salarial, adicional noturno, comissões, gratificações, além de queixas de descontos indevidos, diferença salarial, redução salarial e salário retido. Se consideradas apenas reclamações por diferença salarial, verifica-se que $33,74 \%$ do total de ações constituem reclamações por salários (gráfico 1).

\section{TIPO DE RECLAMAÇÃO MAIS FREQUENTE - Todas as Categorias \\ Universo: 9399 registros}

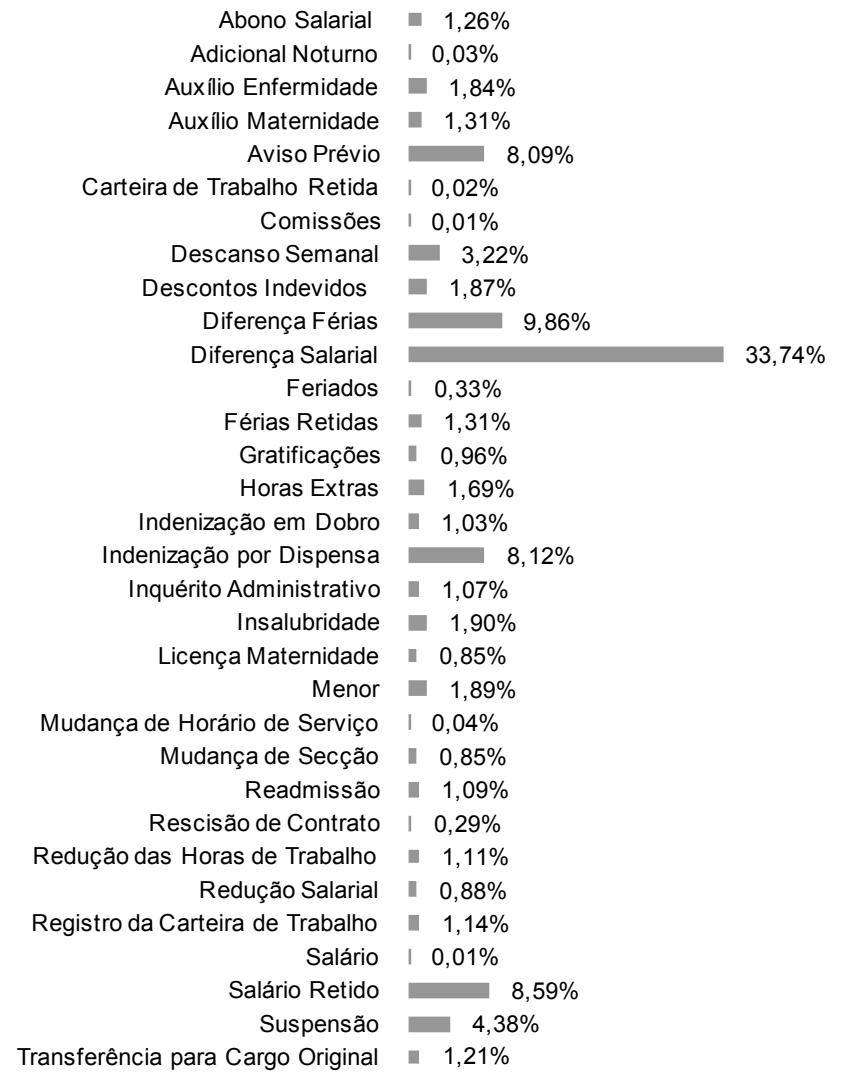

Contudo, a desagregação dos dados por categoria profissional permite-nos constatar que fatores ligados estritamente ao pagamento desencadeiam com mais frequência reclamações entre os têxteis, em contraste com os metalúrgicos. Se consideradas as reclamações por pagamento de abono salarial, adicional noturno, comissões, descontos indevidos, diferença salarial, gratificações, redução salarial e salário retido, constata-se que $48 \%$ dos processos impetrados por têxteis são motivados por fatores de ordem salarial, ao passo que entre os metalúrgicos o índice é de 34\%. Se considerarmos apenas reclamações por diferença salarial, o contraste é ainda mais nítido, com $34,82 \%$ para os têxteis contra apenas $11,34 \%$ para os metalúrgicos (gráficos 2 e 3).

26 A maioria absoluta dos processos foi encaminhada por têxteis (superior a oito mil contra pouco mais de quatrocentos), os quais compunham a maior parte dos empregados na indústria em Juiz de Fora no período estudado. Embora fundamental, a diferença numérica não pode ser tomada como a única razão para explicar uma discrepância tão acentuada no volume de processos impetrados por cada categoria. A segurança/insegurança no emprego, rotatividade empregatícia, evasão da lei pelo patronato constituem, provavelmente, importantes indicadores para explicar tal diferença. Tal objetivo, contudo, foge ao escopo deste artigo. 


\section{TIPO DE RECLAMAÇÃO - Categoria Metalúrgico}

\section{Universo: 432 registros}

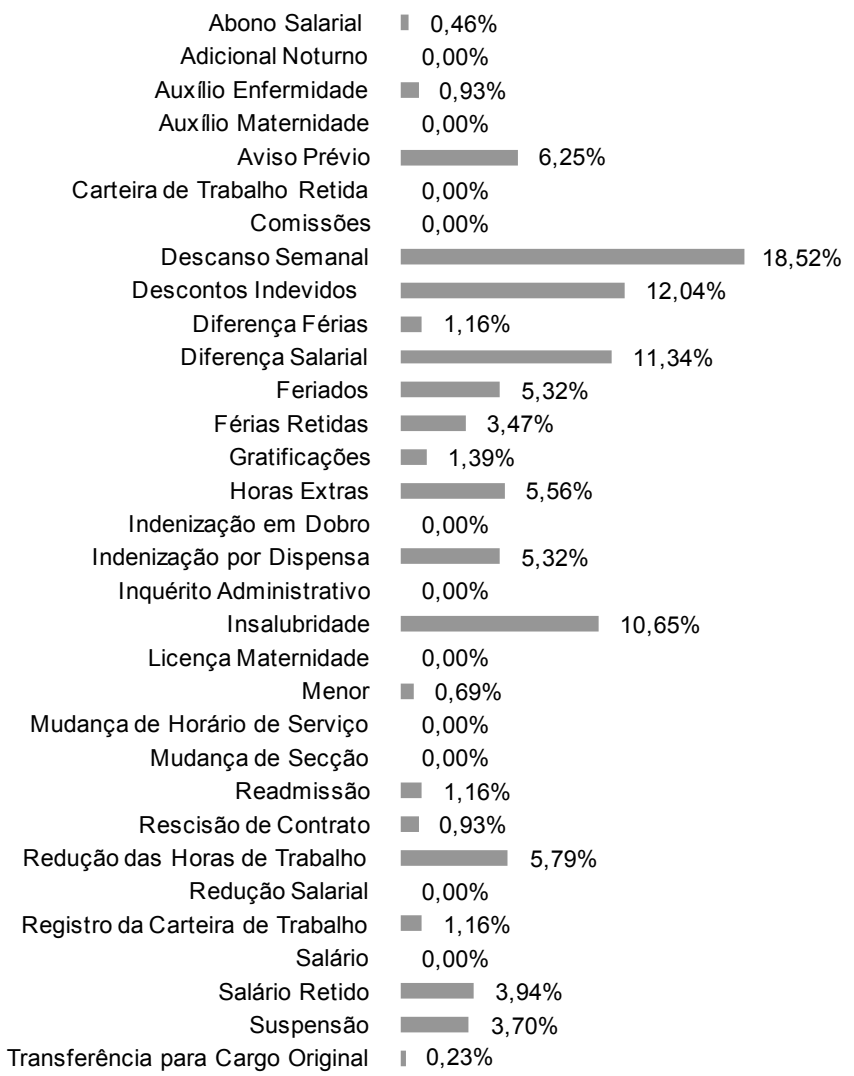

\section{TIPO DE RECLAMAÇÃO - Categoria Têxtil}

\section{Universo: 8967 registros}

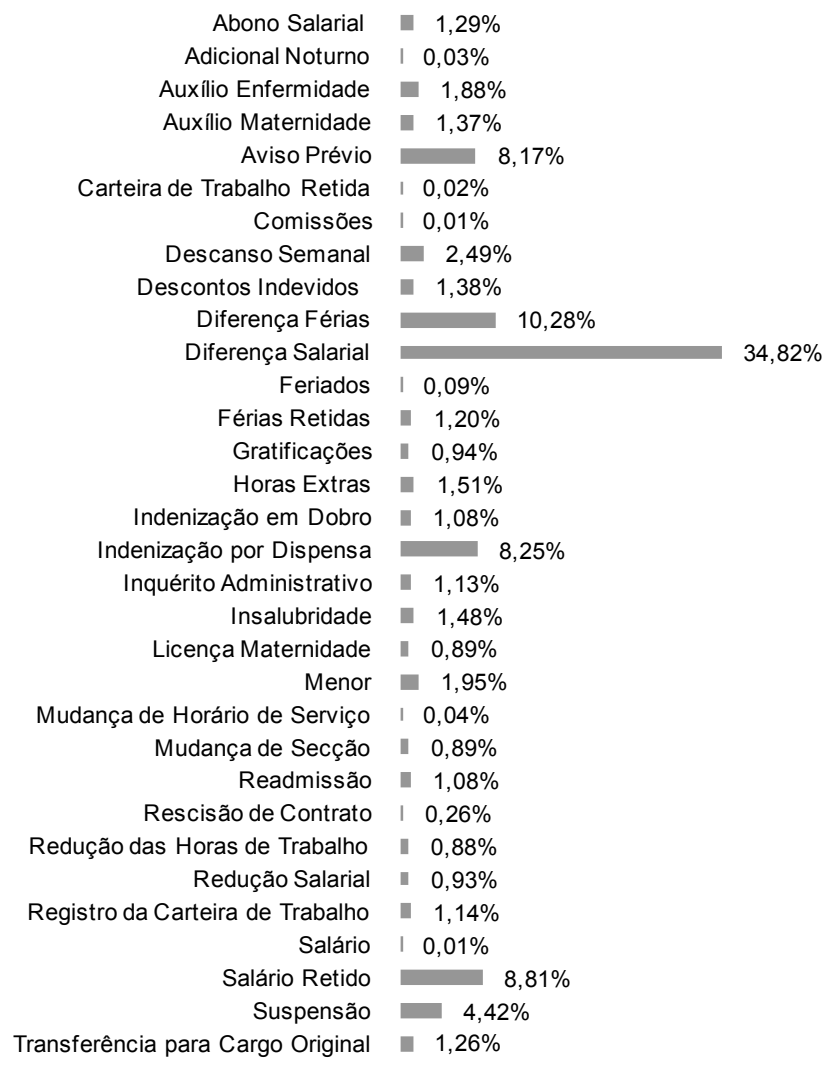


Diante disso, podemos inferir, de antemão, que, à diferença do empresariado do ramo metalúrgico, os proprietários de indústrias têxteis tinham uma maior tendência a burlar os dispositivos legislativos referentes à remuneração do trabalho realizado dentro da jornada ordinária. O salário é, pois, a componente mais importante da exploração do trabalho no ramo têxtil. Em contraste, os metalúrgicos demandavam com mais frequência a redução das horas de trabalho ou o pagamento pelo trabalho realizado em jornada suplementar. ${ }^{27}$

De modo que se tomarmos exclusivamente os dados relacionados às reclamações feitas à Justiça do Trabalho, podemos constatar que os metalúrgicos praticavam jornadas mais extensas que os têxteis e que, ademais, o empresariado do ramo evadia-se com mais frequência da legislação que regulava o descanso remunerado, o limite de horas-extras diárias e a remuneração pelas horas trabalhadas em jornada extraordinária. É o que se depreende da análise das reclamações reunidas nas seguintes categorias: descanso semanal, feriados, férias retidas, horas-extras, insalubridade e redução de horas de trabalho. Em todos esses casos, há significativa "vantagem" para os metalúrgicos. No conjunto, ações desse tipo somam $49,31 \%$ do total de reclamações efetuadas por metalúrgicos, ao passo que entre os têxteis correspondem a apenas 7,65\% (gráficos 2 e 3).

Os dois casos aqui abordados podem ser tomados como ilustrativos do impacto do mercado de trabalho sobre os processos trabalhistas. Isto é, a indústria do ramo metalúrgico está em crescimento no período posterior à Segunda Guerra Mundial e isso se reflete em Juiz de Fora, ainda que o ritmo de crescimento desse tipo de indústria no município não seja tão intenso quanto no centro do estado ${ }^{28}$. De qualquer forma, o volume crescente desses estabelecimentos no município, analisado por Zimbrão de Paula $^{29}$, como vimos acima, contribui para que se observe uma escassez de força de trabalho previamente qualificada para operar as máquinas do setor $^{30}$. Isso supostamente contribui para que o empregador pague salários mais elevados, mas, em contrapartida, exija um tempo de trabalho superior à média do setor industrial, o que faz com que, neste ramo, as reclamações referentes a salários sejam menos significativas que aquelas relacionadas ao tempo de trabalho. Ao passo que a indústria têxtil, um ramo antigo na cidade, conta com um mercado de mão de obra mais vasto e uma força de trabalho menos qualificada, de mais fácil substituição, o que pressiona para baixo os salários da categoria e favorece um comportamento empresarial predatório da legislação referente à remuneração do trabalho praticado em jornada regulamentar. Tal fato parece ser, de certa forma, contrabalançado por uma maior tendência do empresariado do ramo a respeitar a legislação referente à jornada de trabalho, descanso semanal, feriados etc., uma vez que não há pressão por parte do mercado consumidor dos produtos gerados pelo setor têxtil. Isso é o que se constata a partir da análise estritamente quantitativa das fontes.

No entanto, um estudo mais detido de determinados processos trabalhistas demonstra que a reestruturação produtiva que se processava em algumas indústrias

27 A análise qualitativa dos processos indica a existência de dois tipos principais de reclamações referentes ao trabalho realizado em jornada extraordinária, sendo que um tipo refere-se ao pagamento pelo trabalho suplementar e outro diz respeito ao excesso de horas-extras que o reclamante fora levado a praticar. De modo que reclamações referentes a horas-extras podem ou não estar relacionadas à remuneração.

28 SOUZA PAULA, op. cit.; PAULA, op. cit.

29 PAULA, op.cit.

30 Zimbrão de Paula destaca que, nesse período, a qualificação da mão de obra exigida pela indústria metalúrgica é superior à exigida pela indústria têxtil. PAULA, op. cit. Isso tende, supostamente, a elevar a remuneração e mitigar as demissões no setor. 
do ramo têxtil, expressa na introdução de maquinário mais sofisticado, conduzia a uma intensificação do ritmo de trabalho dos operários, levados a operar várias máquinas simultaneamente, dispensando-se, assim, o trabalho suplementar. Ou seja, a aquisição de equipamentos mais modernos, num contexto em que não há crescimento significativo da demanda por produtos gerados na indústria têxtil, induz ao aumento do número de demissões e à intensificação do trabalho daqueles que logram permanecer vinculados à indústria. Elevava-se, pois, a produtividade do trabalhador sem contrapartida do ponto de vista da remuneração, mas também sem abuso do trabalho suplementar realizado por meio de horas-extras, tal como se verifica entre os metalúrgicos.

Tal constatação emana particularmente da análise de processos impetrados por trabalhadores que foram demitidos na iminência de adquirir estabilidade. Em alguns desses casos, o magistrado tende a designar um perito, a fim de levantar a situação da empresa, que em geral justifica a demissão por justa causa em função da reestruturação produtiva decorrente da modernização da fábrica. Conforme mencionamos anteriormente, alguns processos trazem o relatório da perícia, o qual pode conter dados que vão desde a capacidade produtiva do maquinário adquirido até a idade e o tempo de serviço na indústria de todos os operários demitidos, consistindo, pois, numa fonte crucial para informar acerca da reestruturação produtiva do setor e seu impacto sobre os trabalhadores, isto é, desemprego e intensificação do ritmo de trabalho dentro da jornada regulamentar.

Voltando à análise quantitativa processada até aqui, o que cumpre reter é que, se entre os têxteis a face mais perversa da superexploração do trabalho era a baixa remuneração e a intensificação do ritmo de trabalho realizado dentro da jornada ordinária, entre os metalúrgicos ela se manifestava na extensão da jornada, por meio da burla empresarial à legislação referente ao descanso semanal, férias, limite de horas-extras etc. Isso porque, dada a elevada demanda pelo produto gerado pelas indústrias do ramo, os empresários são levados a estender a jornada de seus empregados mesmo nos casos em que a tecnologia empregada permite que se obtenha elevada produtividade do trabalhador no âmbito da jornada regulamentar.

Há, ainda, um último dado a ser considerado que atesta o impacto do mercado de trabalho sobre a Justiça do Trabalho ou, dito de modo mais preciso, sobre o sujeito da ação trabalhista. Já ficou demonstrado que quando o mercado de trabalho se retrai, aumenta o volume de processos trabalhistas. ${ }^{31}$ Esse aumento deriva, sobretudo, do não pagamento de direitos rescisórios, fazendo com que seja mais expressivo o número de processos impetrados por trabalhadores que já não possuem vínculos com a empresa reclamada. Mas também é significativo o número de trabalhadores demitidos que procuram o Judiciário trabalhista para reclamar direitos burlados durante a vigência do contrato. Isso foi constatado para a década de 1990, quando a retração do mercado de trabalho foi compreendida, nos meios empresariais, como caudatária do excesso de direitos. Nesse contexto, embora não se esquivassem de lutar abertamente na arena política pela supressão de tais direitos, os empresários aproveitavam-se das condições adversas para a ação coletiva dos trabalhadores e da redução da ação fiscalizadora do Ministério do Trabalho para burlar a lei ${ }^{32}$, levando os trabalhadores à Justiça do Trabalho após o encerramento do contrato 33

31 Cf., por exemplo: CARDOSO, op. cit.

32 Sobre a redução da fiscalização pelo Ministério do Trabalho, cf.: LOBO, op. cit.

33 Cf.: CARDOSO, op. cit., p.186. 
No período analisado na presente pesquisa, contudo, os trabalhadores tendem com maior frequência a procurar a Justiça do Trabalho para fazer valer seus direitos ainda na vigência do contrato. Com efeito, os gráficos 4 e 5 mostram que $69,42 \%$ dos trabalhadores têxteis e metalúrgicos que reclamaram direitos na Junta de Conciliação e Julgamento de Juiz de Fora no período analisado o fizeram enquanto estavam vinculados à empresa processada. No entanto, num contraste entre têxteis e metalúrgicos, verifica-se que essa tendência é mais significativa entre os metalúrgicos $(83,09 \%)$ do que entre os têxteis $(68,85 \%)$.

Há pelo menos duas interpretações possíveis a partir desses dados. A primeira e mais óbvia é que a demissão na indústria têxtil era mais expressiva naquele ambiente de reestruturação produtiva e de declínio relativo da importância do ramo no conjunto do setor industrial. Portanto, havia um elevado número de trabalhadores têxteis recém-demitidos buscando direitos, inclusive rescisórios, na Justiça do Trabalho. No entanto, essa diferença também pode indicar que o temor diante de uma eventual retaliação patronal a empregados que processam a empresa durante a vigência do contrato era menor entre os metalúrgicos. ${ }^{34}$ Considerando, pois, que naquele contexto o treinamento se fazia preferencialmente on the job, impondo custos ao empregador; que a expansão do setor era recente, não havendo mão de obra treinada disponível no mercado; e que a demanda pelo produto gerado nas fábricas do ramo era crescente, é possível inferir que essa conjunção de fatores inibia as demissões no setor, aumentando a segurança no emprego entre os metalúrgicos e favorecendo a formalização de reclamações na Justiça do Trabalho durante a vigência do contrato. Por contraste, a insegurança no emprego entre os têxteis era maior, pelos motivos já elencados, inibindo a formalização de denúncias pelos empregados.

Em síntese, a configuração do mercado de força de trabalho impelia o empregador do ramo metalúrgico a respeitar a legislação referente à remuneração e a exigir, em contrapartida, a realização de trabalho em jornada suplementar. Diante desse quadro, verifica-se que os trabalhadores metalúrgicos tenderam a acessar a Justiça do Trabalho com maior frequência em nome, não do incremento de seus rendimentos, mas do desrespeito às leis que garantem o descanso semanal, as férias e restringem as horas-extras diárias. No limite, os metalúrgicos reclamaram, sobretudo, da redução das horas trabalhadas. Além disso, dado que havia escassez de força de trabalho adequada disponível no mercado para suprir as necessidades do ramo metalúrgico, esses trabalhadores não temiam a demissão como mecanismo de punição por processarem seus patrões, tendendo com maior frequência a reclamar das condições de trabalho ainda na vigência do contrato (gráficos 4 e 5).

\section{SITUAÇÃO MAIS FREQUENTE POR CATEGORIA - Metalúrgico Universo: 207 registros}

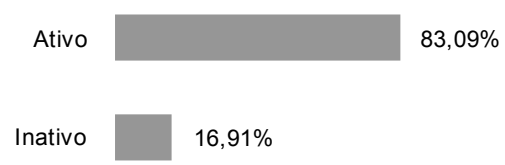

34 Embora essa hipótese pareça razoável, reiteramos a necessidade de comprovação por meio de uma pesquisa qualitativa, pois há situações em que ocorreu justamente o contrário, a exemplo de casos estudados por Sigaud no interior pernambucano, nos quais as tentativas de represália patronal foram respondidas com a intensificação de ações judiciais. Cf.: SIGAUD, op. cit. 


\section{SITUAÇÃO MAIS FREQUENTE POR CATEGORIA - Têxtil \\ Universo: 4983 registros}

Ativo

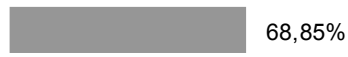

Inativo

$30,78 \%$

O fato de o metalúrgico ir à Justiça do Trabalho durante a vigência do contrato com elevada frequência também pode ser indicativo de que, em contraste com o tecelão, ele dispõe de uma maior segurança quanto à pertinência de suas demandas ou reclamações. Tal afirmação comporta uma forte componente subjetiva, mas os indicadores dos gráficos 6 e 7 fortalecem a hipótese. Com efeito, entre os metalúrgicos, os processos com resultados procedentes $(36,23 \%)$ são mais significativos que os acordos (31,88\%). Somando-se os procedentes com os parcialmente procedentes, tem-se $49,27 \%$. Ao passo que entre os têxteis predominam os acordos (34,10\%) sobre os procedentes (19,17\%). Somando-se os procedentes com os parcialmente procedentes, chega-se a 40,33\% (gráficos 6 e 7).

\section{RESULTADO MAIS FREQUENTE POR CATEGORIA - Metalúrgico}

Universo: 207 registros

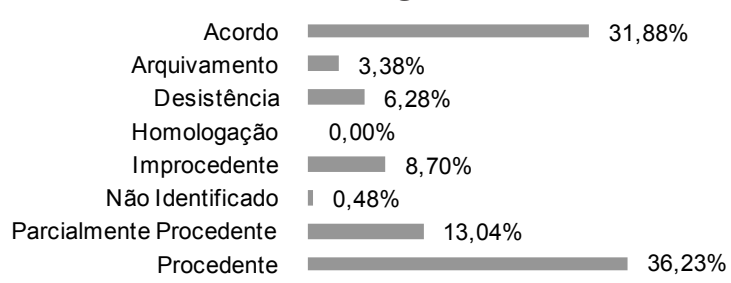

7. RESULTADO MAIS FREQUENTE POR CATEGORIA - Têxtil Universo: 4983 registros

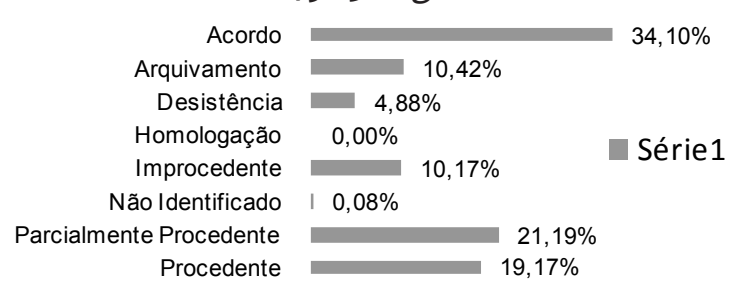

Outra constatação relevante refere-se ao peso da atuação do sindicato. Quando a ação é coletiva ${ }^{35}$, portanto impetrada necessariamente via sindicato, o resultado mais frequente é o procedente, $53,53 \%$. Os acordos correspondem a $26,92 \%$ e as ações julgadas improcedentes representam 6,93\%. Entre as ações individuais, o resultado mais frequente é o acordo, que corresponde a $46,09 \%$, contra $18,95 \%$ de ações procedentes e $15,45 \%$ de improcedentes (gráficos 8 e 9).

35 Ver nota 25 deste artigo. 
8. RESULTADO MAIS FREQUENTE POR TIPO DE AÇÃO - Coletiva

Universo: 3232 registros

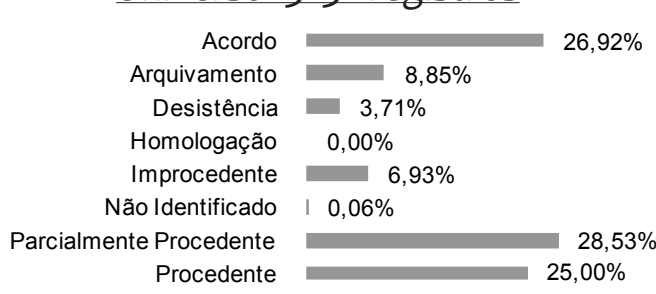

9. RESULTADO MAIS FREQUENTE POR TIPO DE AÇÃO - Individual Universo: 1942 registros

$\begin{array}{rc}\text { Acordo } & 46,09 \% \\ \text { Arquivamento } & 12,36 \% \\ \text { Desistência } & 7,00 \% \\ \text { Homologação } & 0,00 \% \\ \text { Improcedente } & 15,45 \% \\ \text { Não Identificado } & 0,15 \% \\ \text { Parcialmente Procedente } & 7,52 \% \\ \text { Procedente } & 11,43 \%\end{array}$

A partir desses indicadores, é possível inferir que a participação do sindicato, via setor jurídico, fortalece a ação e favorece uma sentença benéfica aos trabaIhadores. É provável que isso decorra da pertinência da ação, da experiência dos advogados, mas deve-se também considerar a própria intensidade do envolvimento do sindicato nessas ações e o impacto que isso produz sobre os resultados. É possível, ainda, formular a hipótese de que as ações coletivas, por envolverem um número maior de pessoas, tendem a exercer uma maior pressão sobre o magistrado, isso se considerarmos que os juízes não são infensos ao ambiente político. Nesse ponto, cumpre ressaltar que por diversas vezes as ações coletivas ocorrem em duas frentes, isto é, ao mesmo tempo em que recorrem ao Judiciário trabalhista, as organizações dos trabalhadores promovem paralisações ou outras formas de protesto, muitas vezes com importante repercussão na imprensa, o que pode afetar as decisões dos magistrados. Pode-se, ainda, vislumbrar a possibilidade de que essas reclamações são, de fato, mais procedentes que as individuais em seus próprios fundamentos, já que o sindicato tende a incentivar os trabalhadores a processarem as empresas quando possui um elevado grau de certeza quanto à procedência da ação. De todo modo, fica demonstrado que a intermediação do sindicato faz diferença para o resultado da ação.

Os dados apresentados até aqui nos permitem indicar diversas tendências acerca do uso da Justiça do Trabalho pelos trabalhadores de dois ramos do setor industrial. Indicamos aqui apenas algumas possibilidades de análise quantitativa, a fim de contribuir para a compreensão acerca do potencial do acervo da Justiça do Trabalho para a pesquisa histórica de natureza quantitativa.

\section{Conclusão}

Na contramão da vertente predominante até o final dos anos de 1970, que via nas instituições criadas sob a égide getulista meros instrumentos de controle sobre os trabalhadores, induzindo-os à passividade, estudos produzidos a partir dos anos de 1980 têm direcionado suas lentes para a ação dos trabalhadores nas 
ruas, nos bairros, nas fábricas, nos sindicatos e também nas instituições. Nesse sentido, o acervo do Judiciário trabalhista, que nos últimos anos tem subsidiado um volume crescente de pesquisas, revela um potencial imensurável para elucidar o conflito capital/trabalho que marca os últimos setenta anos da história da República Brasileira. É desse acervo que extraímos as fontes para a pesquisa que resultou neste artigo.

A questão fundamental que orientou o artigo remete à postura dos trabaIhadores de diferentes categorias profissionais, têxteis e metalúrgicos, para com a Justiça do Trabalho, entre as décadas de 1940 e 1960. Buscou-se compreender se e em que medida as diferenças observadas quanto à situação dos distintos ramos de produção no conjunto da economia se refletiam nas reclamações dos empregados nesses setores ao Judiciário trabalhista.

A pesquisa atestou que as relações de trabalho e os conflitos trabalhistas eram distintos de acordo com o ramo de produção, não obstante verificar-se uma tendência à evasão da norma por parte dos empregadores de ambas as categorias.

No entanto, o empresariado têxtil tendia a burlar com mais frequência a legislação relativa à remuneração do trabalho realizado em jornada ordinária, ao mesmo tempo em que impunha uma intensificação do ritmo de trabalho, por meio da exigência, para que o trabalhador operasse mais de uma máquina simultaneamente. Por seu turno, os empresários do ramo metalúrgico tendiam a evadir-se com mais frequência das normas relativas ao tempo de trabalho, o que se traduzia na retenção das férias de seus funcionários, no desrespeito aos feriados ou no uso abusivo das horas-extras.

Por outro lado, a maioria absoluta dos metalúrgicos procurava a Justiça do Trabalho para fazer valer seus direitos ainda na vigência do contrato, isto é, enquanto estava vinculada à empresa reclamada. De sua parte, a maioria dos tecelões também recorria ao Judiciário preferencialmente na vigência do contrato, mas era mais significativo do que entre os metalúrgicos o número de têxteis que formalizava reclamação após o encerramento do contrato de trabalho. Isso pode ser indicativo de que o metalúrgico, por dispor de maior qualificação e ocupar um lugar no mercado de trabalho que se encontrava em expansão no período analisado, não temia tanto quanto o têxtil a perda do emprego por acionar na Justiça o empregador.

A pesquisa indicou, ainda, que os metalúrgicos obtiveram mais resultados favoráveis em suas ações que os têxteis e que em ambos os casos a participação do sindicato produziu impacto positivo, do ponto de vista dos reclamantes, sobre as decisões dos magistrados.

Como advertimos diversas vezes ao longo deste artigo, a abordagem aqui processada está longe de encerrar as questões que envolvem a Justiça do Trabalho no Brasil. Na realidade, mais fomenta indagações do que as responde. De todo modo, se inscreve numa corrente historiográfica que tem buscado perscrutar novas fontes, a fim de contribuir para a compreensão acerca de um contexto que, a despeito de há muito frequentar os anais da Sociologia, da Ciência Política e mesmo da História, durante muito tempo mais suscitou a fixação de rótulos e a formulação de teorias do que estudos baseados em funda empiria.

Recebido em 24/01/2013 Aprovado em 2/05/2013 